\title{
BAGAIMANA KUALITAS KEHIDUPAN KERJA BERPENGARUH TERHADAP MOTIVASI KERJA KARYAWAN
}

\author{
Jennifer \\ Sriwindany Sihombing \\ Yufan Tri Maimun Zebua \\ Gissele Rosemaria \\ Tengku Intan Khairany \\ Sri Hartini \\ Fakultas Psikologi \\ Universitas Prima Indonesia \\ Jalan Sekip Medan, Indonesia
}

\begin{abstract}
This study aims to find out whether there is a relationship between the quality of life and work motivation of the employees of PT. Clipan Finance Indonesia Tbk. Medan, North Sumatra. The hypothesis proposed that there is a positive relationship between the quality of work life and work motivation of employees of PT. Clipan Finance Indonesia Tbk. The population in this study are 127 employees. The sample used was 109 people. The sampling technique used was purposive sampling. The method used is a quantitative method. The research data were collected using a quality of life scale with 44 items and a work motivation scale with 26 items. The data collected was then performed an assumption test consisting of normality and linearity tests. After fulfilling the requirements, a Product Moment analysis is carried out with the help of the SPSS 21 program for Windows. The results obtained are that there is a positive relationship between the variables of the quality of work life and work motivation of the employees of PT. Clipan Finance Indonesia, Tbk. The product moment value obtained is $r=$ $0,684$ with sig. 0.000 ( $p<0.05)$. The value of the effective contribution of the quality of work life variable to work motivation is 46,8 percent, the remaining 53,2 percent was influenced by other things that are not examined.
\end{abstract}

Keywords: work life quality; working motivation

Abstrak--Penelitian ini memiliki tujuan agar dapat mencari tahu ada tidaknya hubungan antara kualitas kehidupan kerja dan motivasi kerja pada karyawan PT. Clipan Finance Indonesia Tbk. Medan, Sumatera Utara. Hipotesis yang diajukan ialah adanya hubungan positif antara kualitas kehidupan kerja dan motivasi kerja pada karyawan PT. Clipan Finance Indonesia Tbk. Populasi pada penelitian ini berjumlah 127 karyawan. Sampel penelitian adalah 109 orang. Penelitian ini menggunakan teknik sampling Purposive Sampling. Metode yang digunakan adalah metode 
kuantitatif. Data penelitian dikumpulkan menggunakan skala kualitas kehidupan kerja dengan 44 butir aitem dan skala motivasi kerja dengan 26 butir aitem. Data yang berhasil dikumpulkan kemudian dilakukan uji asumsi yang terdiri dari uji normalitas dan linearitas. Setelah memenuhi syarat kemudian dilakukan analisis korelasi Product Moment yang dibantu dengan program SPSS 21 untuk Windows. Hasil penelitian yang diperoleh adalah terdapat hubungan positif antara variabel kualitas kehidupan kerja dan motivasi kerja pada karyawan PT. Clipan Finance Indonesia, Tbk. Nilai korelasi Product Moment yang diperoleh adalah $r=0,684$ dengan sig. $0,000$ ( $\mathrm{p}<0,05)$. Nilai sumbangan efektif variabel kualitas kehidupan kerja terhadap motivasi kerja adalah 46,8 persen, sisanya 53,2 persen dipengaruhi hal-hal lain yang tidak diteliti.

Kata kunci: kualitas kehidupan kerja, motivasi kerja

\section{PENDAHULUAN}

Perusahaan adalah tempat yang dimiliki sekumpulan orang yang mempunyai tujuan bisnis. Agar bisa mempraktikkan prinsip bisnis yang baik dan benar serta menyesuaikan pada kearifan lokal dan prinsip etika yang lain, untuk itu butuh disusun suatu panduan pedoman etika bisnis perusahaan. Isi pedoman ini wajib memasukkan sikap perusahaan sebagai entitas bisnis, termasuk juga perilaku para pemimpin dan pekerja yang semuanya adalah anggota dari entitas bisnis tersebut (KNKG (Komite Nasional Kebijakan Governance), 2010).

Di dalam sebuah perusahaan ada yang dinamakan dengan organisasi, sebagaimana organisasi merupakan bagian dari sebuah perusahaan yang memiliki berbagai jenis jabatan dan pekerjaannya. Organisasi dalam perusahaan diisi oleh para pekerja yang bekerja dalam perusahaan dimana organisasi tersebut berdiri. Organisasi dalam sebuah perusahaan juga mempengaruhi kinerja dari setiap karyawan atau anggota di dalamnya.

Manajemen sumber daya manusia (MSDM) ialah hal penting dalam mencapai tujuan sebuah perusahaan atau organisasi, dan tantangan yang akan dihadapi perusahaan atau organisasi dimasa depan adalah cara memperoleh sumber daya manusia (SDM) yang memiliki kualitas, mampu berinovasi, serta cara berpikir yang kreatif. Dessler (dalam Sutrisno, 2009), menyatakan kalau sumber daya manusia bisa diartikan sebagai kebijakan yang diperlukan seseorang untuk menjalankan aspek sumber daya manusia dari posisi manajemennya, terdiri dari merekrut karyawan, melakukan seleksi, menyusun pelatihan, pengupahan, dan umpan balik. Hasibuan 
(dalam Johar \& Fauzi, 2007), mengatakan pengertian sumber daya manusia sebagai ilmu yang mengatur hubungan peranan tenaga kerja agar berfungsi secara efektif dan juga efisien mewujudkan maksud dari perusahaan, tenaga kerja, serta karyawannya.

Untuk itu sebuah perusahaan harus memberikan loyalitas dan motivasi untuk meningkatkan kinerja karyawan dan memberikan pelayanan yang sepadan kepada karyawan dalam mengerjakan tugas mereka sehingga dapat menghasilkan hasil kerja yang baik serta memuaskan dan tujuan bersama tercapai.

Dalam perusahaan atau organisasi dapat terjadi beberapa permasalahan yang dipicu oleh berbagai hal, contohnya kasus karyawan yang mogok bekerja. Hal ini terjadi di Jakarta International Container Terminal (JICT), hal ini terjadi karena mogok kerja yang dilakukan oleh karyawannya, sebanyak 650 karyawan lebih melaksanakan aksi mogok kerja di daerah lobi kantor JICT, mogok kerja tersebut dikarenakan perpanjangan kontrak dan pemotongan hak pekerja sebesar 42 persen. Mogok kerja tersebut akan berlangsung dari tanggal 3 Agustus 2017 hingga 10 Agustus 2017 (www.kompas.com).

Kasus yang lain terjadi pada perawat di RSUD Ako Mamuju, mogoknya perawat yang berada di RSUD Ako Mamuju karena upah yang diberikan tidak sesuai dengan ketentuan yang sudah di sepakati. Akibat dari mogoknya perawat tersebut, seluruh bagian RSUD Ako Mamuju mengalamai kelumpuhan sementara, namun kejadian tersebut tidak berlangsung lama, karena pihak rumah sakit langusng datang dan bernegosiasi dengan para perawat di RSUD Ako Mamuju. (www.sindonews.com).

Selain kedua kasus diatas, kasus lain ada juga terkait dengan karyawan PT. Freeport yang mogok kerja karena tuntutan yang tidak tepenuhi. Pada tanggal 1 Mei 2017 karyawan yang masuk ke dalam 14 pimpinan unit kerja (PUK) melakukan mogok kerja karena tuntutan mereka tidak tepenuhi, mogok kerja yang dilakukan oleh karyawan PT. Freeport itu berlangsung dari 1 Mei 2017 hingga 30 Mei 2017, dan karyawan menunggu itikat baik dari pihak majemen PT. Freeport (www.cnnindonesia.com).

Fenomena yang sama juga terjadi pada karyawan PT. Clipan Finance Indonesia, Tbk, Medan-Sumatera Utara. Peristiwa ini bisa diketahui dari wawancara serta observasi yang peneliti lakukan terhadap beberapa karyawan yang bekerja di PT. Clipan Finance Indonesia, Tbk. Medan- 
Sumatera Utara. Menurut para pekerja bahwa mereka sering merasakan kurang bersemangat saat bekerja, kurangnya rasa semangat tersebut terlihat pada saat bekerja baik dilapangan ataupun dikantor. Para pekerja terlihat kurang bersemangat dan malas-malasan saat sedang bekerja. Ini dapat terjadi dikarenakan insentif yang diterima mereka tidak sesuai dengan yang telah ditetapkan, karena diperusahaan tersebut memiliki sistem target kerja dengan target penjualan dimana mereka harus menjual kendaraan beroda dua dan empat, dengan minimal lima dan dua unit setiap bulan oleh masing-masing karyawan.

Selain itu mereka juga harus menanggung kritikan dari atasan jika ada tunggakan penjualan yang belum dilunaskan oleh konsumen. Ini membuat munculnya rasa kurang menghargai antara atasan dengan bawahan, atasan sering kali menekan para karyawannya dengan segala kritikan dari konsumen. Ini juga menjadi alasan untuk membuat karyawan malas untuk bekerja lewat dari jam kerja yang ditetapkan dan tidak memberikan upah lembur sama sekali. Hal ini menyebabkan kinerja para karyawan menurun, hasil yang diharapkan tidak sesuai dengan rencana yang dibuat oleh perusahaan.

Berdasarkan beberapa kasus diatas dapat dilihat berbagai permasalahan seperti tuntutan yang tidak terpenuhi, upah yang diberikan tidak sesuai dengan kesepakatan, dan kebijakan yang kurang tepat bagi karyawan dapat menyebabkan mereka melakukan tindakan mogok kerja dan tidak memiliki dorongan atau motivasi dalam bekerja.

Menurut Pritchard dan Ashwood (dalam Kanfer et al., 2008) motivasi kerja dapat diartikan sebagai suatu proses psikis yang memberi arah atau energi, banyaknya tindakan, dan kerajinan tindakan secara berkelanjutan dari apa yang dialami seseorang yang berpengaruh pada penentuan orang tersebut dalam hubungan dirinya dan pekerjaannya. Motivasi kerja juga berarti sebagai keseriusan dan tindakan individu dalam melaksanakan pekerjaannya untuk mencapai tujuan perusahaan selain tujuan individu itu sendiri (Wijono, 2010).

Ada beberapa faktor yang bisa mempengaruhi motivasi kerja, salah satunya kualitas kehidupan kerja. Sebagaimana hasil penelitian yang diperoleh Astitiani \& Surya (2016), pada 60 karyawan di Swastika Bungalows Sanur. Hasil penelitian ini, dapat diketahui bahwa kualitas kehidupan kerja yang semakin baik akan berpengaruh pada motivasi karyawan yang semakin tinggi. Ini berdampak juga pada kepuasan kerja karyawan. Hasil penelitian ini bisa menjadi acuan 
bagi perusahaan dalam menambah kesejahteraan karyawan melalui perbaikan keamanan kerja menjadi lebih baik, memberi keleluasaan pada pekerja, serta meningkatkan bonus yang diterima oleh karyawan. Ini akan sangat berpengaruh positif pada perbaikan produktivitas perusahaan.

Menurut Hariandja (2002), kualitas kehidupan kerja adalah cara memenuhi kebutuhan karyawan dengan memberi kesempatan pada karyawan untuk mengambil keputusan penuh dalam merencanakan kehidupan kerja mereka.

Hasil penelitian ini dilakukan oleh Hasmalawati \& Restya (2017), dapat diketahui terdapat pengaruh kuat antara kualitas kehidupan kerja dengan motivasi kerja. Hasil ini berarti hipotesis yang mengatakan bahwa motiviasi kerja merupakan faktor yang berpengaruh pada kualitas kehidupan kerja seseorang dapat diterima. Kualitas kehidupan kerja dan motivasi kerja sangat berpengaruh pada kinerja dan seberapa produktif para karyawan tersebut.

Kualitas kehidupan kerja menjadi faktor utama dalam memicu timbulnya motivasi kerja hal ini dapat dibuktikan pada penelitian yang dilaksanakan oleh Maemunah et al. (2015). Pada penelitian yang dilangsungkan di Sheraton Bandung Hotel dan Towers dengan jumlah responden sebanyak 107 karyawan dan mendapatkan hasil penelitian yang menyatakan bahwa kedua variabel ini memiliki hubungan signifikan dan positif.

Selain motivasi kerja, terdapat faktor lain yang dapat berpengaruh pada motivasi kerja yaitu gaya kepemimpinan. Sebagaimana penelitian yang dilakukan oleh Afrizal (2016), di BMT Bina Ihsanul Fikri Yogyakarta. Pada penelitian ini, total sampel yang diambil sebanyak 66 orang pegawai. Dari hasil penelitian dapat dilihat terdapat hubungan positif antara gaya kepemimpinan dengan motivasi kerja pekerja. Selain gaya kepemimpinan, budaya organisasi juga bisa mempengaruhi motivasi kerja sebagaimana penelitian yang dilakukan Fatmawati (2012), pada 175 orang karyawan IAIN Ar-Raniry Banda Aceh. Hasil penelitian menunjukan budaya organisasi memiliki hubungan positif dengan motivasi kerja pada karyawan IAIN Ar-Raniry Banda Aceh.

Berdasarkan uraian di atas, dengan melihat berbagai fenomena yang menyebabkan menurunnya motivasi kerja pada karyawan, adanya karyawan yang lalai, tidak bertanggung jawab atas pekerjaannya, hingga menyebabkan kerugian yang harus ditanggung oleh perusahaan maupun para pegawai itu sendiri sebagai akibat dari kualitas kehidupan kerja yang tidak 
nyaman. Dari penjelasan tersebut, peneliti akan melaksanakan penelitian tentang Motivasi kerja dan Kualitas kehidupan kerja pada karyawan di PT. Clipan Finance Indonesia Tbk. MedanSumatera Utara.

\section{METODE}

\section{Partisipan}

Metode pada penelitian ini adalah metode kuantitatif. Jumlah populasi adalah sebanyak 127 orang karyawan PT. Clipan Finance Indonesia, Tbk. Jumlah sampel yang diambil untuk penelitian berdasarkan pada ketentuan yang diungkap oleh Isaac dan Michael yaitu sebanyak 109 orang dengan taraf kesalahan $1 \%$. Teknik pengambilan sampel menggunakan purposive sampling berdasarkan ketentuan yang telah ditetapkan sebelumnya sebelumnya.

\section{Desain}

Untuk pengumpulan data, peneliti menggunakan 2 skala, yaitu skala motivasi kerja dan skala kualitas kehidupan kerja. Kedua skala ini menggunakan metode skala Likert. Terdapat empat pilihan jawaban pada setiap pernyataan skala. Pilihan tersebut terdiri dari SS (sangat setuju), S (setuju), TS (tidak setuju), dan STS (sangat tidak setuju). Setiap jawaban pernyataan akan diberikan poin berdasarkan pilihan jawaban mereka. Poin yang diberikan berada pada rentang 1 (satu) sampai 4 (empat). Untuk pernyataan favourable, nilai 4 (empat) diberikan pada pilihan sangat setuju, nilai 3 (tiga) diberikan pada pilihan setuju, nilai 2 (dua) pada pilihan tidak setuju, serta 1 (satu) pada pilihan sangat tidak setuju. Ini berlaku sebaliknya untuk pernyataan yang unfavourable.

Skala motivasi kerja disusun berdasarkan aspek motivasi kerja menurut Priansa, (2014) yaitu usaha (9 aitem), ketekunan (10 aitem), dan arah (7 aitem). Total aitem untuk skala ini berjumlah 26 aitem. Nilai reliabilitas $\alpha$ dari skala ini adalah sebesar 0,859 dengan nilai r berada pada rentang 0,300 hingga 0,673. Skala kualitas kehidupan kerja disusun berdasarkan aspek kualitas kehidupan kerja yang dikemukakan oleh Dahl, dkk., (2009). Aspek ini terdiri dari pekerjaan intrinsik (7 aitem), keterampilan belajar sepanjang hayat dan pengembangan karir (10 
aitem), kesetaraan gender ( 9 aitem), kesehatan dan keselamatan kerja ( 9 aitem), serta fleksibilitas dan keamanan (9 aitem). Jumlah aitem adalah 44 aitem. Koefisien korelasi (r) bergerak dari 0,302 hingga 0,587. Sedangkan koefisien reliabilitas skala kualitas kehidupan kerja bernilai sebesar 0,964 .

\section{Prosedur}

Sebelum dilakukannya penelitian, peneliti melakukan uji coba skala penelitian terdahulu terhadap subjek sejenis dengan subjek penelitian. Tujuan dilakukannya uji coba ini adalah agar dapat memperoleh skala yang memiliki nilai validitas dan reliabilitas baik. Aitem skala yang memiliki validitas kurang memadai akan dibuang.

\section{Teknik Analisis}

Pengolahan data ini menggunakan teknik Korelasi Product Moment Pearson. Tahap pertama sebelum melakukan uji korelasi, dilakukan terlebih dulu uji asumsi yang terdiri dari uji normalitas dan liniearitas.

Analisis data menggunakan bantuan program lunak SPSS Statistics 21 for windows.

\section{ANALISIS DAN HASIL}

\section{Uji Asumsi}

Hasil analisis data menggunakan SPSS diperoleh koefisien hasil uji normalitas KS-Z = 1,216 dengan Sig sebesar 0,104 untuk uji 2 (dua) arah dan sig sebesar 0,052 untuk uji 1 (satu) arah $(\mathrm{p}>0,05)$. Angka ini memiliki arti bahwa variabel mtivasi kerja memiliki sebaran atau distribusi normal. Untuk variabel kualitas kehidupan kerja diketahui nilai KS-Z =0,489 dan Sig sebesar 0,970 untuk uji 2 (dua) arah sedangkan untuk uji 1 (satu) arah diperoleh nilai 0,485 (p > 0,05) sehingga variabel kualitas kehidupan kerja juga memiliki sebaran yang normal. Hasil uji normalitas dapat dilihat di tabel 1. 
Selanjutnya akan dibahas hasil uji linearitas. Dari uji linearitas tersebut dapat diperoleh nilai signifikansi sebesar 0,000 dimana $\mathrm{p}<0,05$, memiliki makna jika kedua variabel tersebut dikatakan linear. Nilai uji asumsi terdapat pada tabel 2 dibawah.

Dengan nilai kedua uji asumsi yang telah dilakukan yang memenuhi persyaratan, maka analisis Pearson Product Moment Correlation dapat dilakukan.

\section{Uji Hipotesis}

Pada uji hipotesis, analisis data menggunakan uji hipotesis Pearson Correlation. Tabel nilai uji hipotesis dapat dilihat pada tabel 3 di bawah.

Dari uji korelasi antara motivasi kerja dan kualitas kehidupan kerja, dapat diketahui nilai korelasi product moment adalah 0.684 dengan sig sebesar 0.000 ( $\mathrm{p}<0.05)$. Hasil ini memiliki arti adanya hubungan positif antara motivasi kerja dan kualitas kehidupan kerja. Dari hasil yang sudah diperoleh, maka hipotesis penelitian ini dapat diterima. Hasil penelitian memperoleh nilai sumbangan efektif koefisien determinasi $\left(\mathrm{R}^{2}\right)$ sebesar 0.468 . Ini berarti 46,8 persen motivasi kerja mempengaruhi kualitas kehidupan kerja dan sisanya 53,2 persen dipengaruhi oleh faktor lain, gaya kepemimpinan, lingkungan kerja, stres kerja, sistem penilaian kompetisi, budaya organisasi, dan kompensasi.

Pada penelitian yang telah dilaksanakan pada karyawan PT. Clipan Finance Indonesia, Tbk. dapat diambil kesimpulan antara variabel motivasi kerja dan kualitas kehidupan kerja memiliki hubungan yang positif. Nilai koefisien korelasi Product Moment sebesar $\mathrm{r}=0,684$ dan nilai signifikansi $\mathrm{p}=0,000(\mathrm{p}<0,05)$, ini berarti semakin baik kualitas kehidupan kerja karyawan akan berdampak pada meningkatnya motivasi kerja karyawan. Ini berlaku juga untuk sebaliknya. Semakin buruk kualitas kehidupan kerja akan berdampak pada menurunnya motivasi kerja.

Tabel 1.

Hasil Uji Normalitas

\begin{tabular}{|l|l|l|l|l|l|}
\hline Variabel & SD & KS-Z & Sig. & P & Keterangan \\
\hline Motivasi Kerja & 9,851 & 1,216 & 0,052 & $\mathrm{p}>0,05$ & Sebaran normal \\
\hline $\begin{array}{l}\text { Kualitas } \\
\text { Kehidupan Kerja }\end{array}$ & 12,025 & 0,489 & 0,485 & $\mathrm{p}>0,05$ & Sebaran normal \\
\hline
\end{tabular}


Tabel 2.

Hasil Uji Asumsi

\begin{tabular}{|l|l|l|l|}
\hline Variabel & F & Sig & Keterangan \\
\hline $\begin{array}{l}\text { Motivasi Kerja } \\
\text { Kualitas Kehidupan } \\
\text { Kerja }\end{array}$ & 123,564 & 0.000 & Linear \\
\hline
\end{tabular}

Tabel 3.

Hasil Uji Hipotesis

\begin{tabular}{|l|l|l|}
\hline Variabel & Pearson Correlation & Signifikansi (p) \\
\hline $\begin{array}{l}\text { Motivasi kerja } \\
\text { Kualitas Kehidupan } \\
\text { Kerja }\end{array}$ & 0.684 & 0.000 \\
\hline
\end{tabular}

\section{DISKUSI}

Pada data penelitian di atas, hasil motivasi kerja dengan kualitas kehidupan kerja memiliki hubungan positif. Hasil penelitian ini satu arah dengan penelitian Hasmalawati dan Restya (2017), pada 54 karyawan di Puskesmas Paya Bokong Aceh Utara. Penelitian ini memiliki kesimpulan bahwa kualitas kehidupan kerja dengan motivasi kerja berpengaruh dengan nilai 42,3 persen dan nilai $\mathrm{F}=38,199$ serta nilai $\mathrm{p}=0,000$ yang bermakna variabel kualitas kehidupan kerja memiliki pengaruh terhadap variabel motivasi kerja sebesar 42,3 persen.

Dari data penelitian yang diperoleh peneliti, karyawan PT. Clipan Finance Indonesia, Tbk. menunjukkan motivasi kerja yang cenderung tinggi, ada sejumlah 9 pekerja yang memiliki motivasi kerja yang rendah dengan persentase 8,3 persen. Terdapat beberapa karyawan yang sering melakukan motivasi kerja kerja secara verbal sedangkan motivasi kerja kerja yang lain seperti fisik, mempromosikan diri, dan bekerja dengan teliti dan dalam bekerja bersemangat yang tidak nampak banyak. Selanjutnya sejumlah 23 orang yang memiliki persentase 21,1 persen terlihat motivasi kerjanya yang sedang, dengan tingkat ini, para pekerja ini melakukan motivasi kerja verbal lebih sering, menonjolkan diri sebagai karyawan terbaik dan disertai berapa tindakan motivasi kerja fisik. Sementara karyawan yang memilik motivasi kerja yang tinggi 77 karyawan 70,6 persen.

Uraian di atas dapat diketahui berdasarkan hasil observasi dan wawancara peneliti. Hasil observasi dan wawancara pada beberapa karyawan adalah sebagai berikut. Pada karyawan yang 
memiliki motivasi kerja yang rendah, mereka cenderung melakukan, seperti bergosip dengan rekan kerja tentang kebijakan atasan, kinerja rekan kerja, dan tentang kehidupan kerja temantemannya, menguap di sembarangan, malas-malasan, berdiri sambil memainkan ponsel mereka setelah mendapat teguran dari atasan, dan saling menyalahkan ketika terjadi kesalahan di tempat kerja. Beberapa karyawan pada kategori ini mengatakan ingin fokus bekerja dengan baik, menjaga sikap, dan tidak mau terlibat banyak masalah dengan orang lain supaya mereka mendapatkan kesempatan promosi dari perusahaan untuk jenjang karir mereka. Aspek motivasi kerja yang lain yaitu semangat untuk menduduki jabatan yang tinggi, dan semangat untuk menguasai orang. Motivasi kerja verbal yang lebih tinggi ada pada karyawan yang masuk kategori sedang. Hasil observasi dan wawancara dilakukan untuk atasan dapat memberikan arahan kepada karyawan yang menggunakan kata-kata penyemangat untuk bawahannya, terlihat ada beberapa orang karyawan yang sedang memberi arahan untuk para karyawan yang baru kerja, memberikan penjelasan apa saja yang akan mereka kerjakan dan bagaimana cara untuk membuat konsumen membeli kendaraan yang mereka pasarkan.

Pada kategori motivasi kerja yang tinggi, terdapat 77 orang. Karyawan yang memiliki motivasi kerja yang tinggi ini memiliki hubungan yang baik dengan orang disekitarnya, cara berbicara yang lembut dan bijak sana yang membuat banyak orang terpengaruh dengan apa yang dia ucapakan, memberikan arahan yang baik. Beberapa rekan kerja yang sering melatih dirinya bagaimana cara mempromosikan produk kepada pelanggan dan pelanggan mau membeli produk tersebut. Semua aspek agresi yaitu motivasi kerja dapat terlihat dengan jelas pada karyawan ini.

Pada karyawan PT. Clipan Finance Indonesia, Tbk. Medan tidak memiliki pekerja yang kualitas kehidupan kerjanya rendah. Rata-rata kualitas kehidupan kerja mereka berada pada kisaran tingkat tinggi. Sejumlah 43 pekerja yang memiliki persentase 39,4 persen memperlihatkan kualitas kehidupan kerja sedang. Sebanyak 66 karyawan dengan persentase 60,6 persen memiliki kualitas kehidupan kerja yang tinggi. Pada karyawan dengan kualitas kehidupan kerja sedang, mereka terlihat bekerja secara normal, tidak terjadi perselisihan yang berarti di sini, kedisiplinan karyawan yang lumayan baik serta keinginan karyawan untuk bekerja sesuai dengan prosedur. Pada karyawan dengan kehidupan kerja yang tinggi cenderung dialami oleh karyawan pada bagian penjualan. Dapat dilihat dari kebiasaan mereka yang selalu terlihat bersemangat 
untuk mengejar target penjualan, pekerjaan yang terlihat fleksibel, tidak adanya tekanan kerja yang berarti, serta bonus untuk pencapaian target yang lumayan tinggi.

\section{KESIMPULAN DAN SARAN}

\section{Kesimpulan}

Dari penelitian yang dilakukan sebelumnya, peneliti dapat menarik kesimpulan bahwa hipotesis penelitian yang berbunyi motivasi kerja dan kualitas kehidupan kerja memiliki hubungan yang positif. Nilai koefisien korelasi Product Moment (r) yang diperoleh adalah 0,684, dan signifikan (p) sebesar 0,000 ( $<<0,05)$. Nilai sumbangan efektif variabel kualitas kehidupan kerja terhadap motivasi kerja adalah 46,8 persen, selebihnya 53.2 persen dipengaruhi oleh faktor lain yang belum diteliti, seperti gaya kepemimpinan, lingkungan kerja, stres kerja, sistem penilaian kompetensi, budaya organisasi, dan kompensasi.

\section{Saran}

Peneliti dapat memberikan saran terhadap karyawan dengan melakukan beberapa hal berikut untuk menciptakan sebuah lingkungan kerja yang menyenangkan: karyawan belajar lebih memahami bagaimana situasi lingkungan kerja dan menyesuaikan diri. Ada baiknya setiap karyawan membangun pola pikir positif dan perilaku saling membantu satu sama lain, memiliki kontrol diri yang lebih baik, dapat menerima kritik dan saran untuk meningkatkan kualitas diri masing-masing, serta karyawan dapat membuat sebuah perkumpulan untuk melakukan kegiatan bersama yang positif agar dapat melepas diri dari kejenuhan dan kelelahan saat bekerja yang dapat meningkatkan kekompakan dan keakraban antar karyawan.

Untuk pimpinan perusahaan, peneliti menyarankan agar dapat memberi perhatian lebih pada karyawan dengan cara memberi penghargaan dan promosi pada karyawan berprestasi, menciptakan jenjang karir yang jelas, memberi insentif yang tepat, dan membuat suasana tempat kerja yang lebih leluasa dan nyaman, membuat kegiatan-kegiatan yang seru dan menyenangkan untuk mengurangi kejenuhan karyawan. 


\section{REFERENSI}

Afrizal, A. (2016). PENGARUH GAYA KEPEMIMPINAN TERHADAP MOTIVASI KERJA DAN KEPUASAN KERJA SERTA DAMPAK PADA KINERJA KARYAWAN (Studi Kasus BMT Bina Ihsanul Fikri Yogyakarta). JESI (Jurnal Ekonomi Syariah Indonesia), 5(2), 151. https://doi.org/10.21927/jesi.2015.5(2).151-170

Astitiani, N. L. P. S., \& Surya, I. B. K. (2016). Pengaruh Quality of Work Life Terhadap Motivasi Kerja Dan Kepuasan Kerja Karyawan. Matrik: Jurnal Manajemen, Strategi Bisnis Dan Kewirausahaan, 10(2), 156. https://doi.org/10.24843/matrik:jmbk.2016.v10.i02.p06

Hariandja, M. T. E. (2002). Manajemen sumber daya manusia. Grasindo.

Hasmalawati, N., \& Restya, W. P. D. (2017). HUBUNGAN KUALITAS KEHIDUPAN KERJA TERHADAP MOTIVASI KERJA KARYAWAN DI PUSKESMAS PAYA BAKONG ACEH UTARA. JURNAL SAINS PSIKOLOGI, 6(2), 63-67. https://doi.org/10.17977/um023v6i12017p063

Johar, A., \& Fauzi, A. (2007). Aplikasi Excel dalam Aspek Kuantitatif Manajemen Sumber Daya Manusia. Edisi Pertama, Elex Media Komputindo, Jakarta.

Kanfer, R., Chen, G., \& Pritchard, R. D. (2008). Work motivation: Past, present and future. Routledge.

KNKG (Komite Nasional Kebijakan Governance). (2010). Pedoman Etika Bisnis Perusahaan. PT. Elex Media Komputindo.

Maemunah, I., Sadkar, U. H., \& Ryana, H. (2015). PENGARUH KUALITAS KEHIDUPAN KERJA TERHADAP MOTIVASI KERJA KARYAWAN DI SHERATON BANDUNG HOTEL \& TOWERS. JURNAL BARISTA, 2(1). https://stpbandung.ac.id/ejournal/index.php/v01/article/view/33

Sutrisno, E. (2009). Manajemen sumber daya manusia edisi pertama. Jakarta: Kencana Prenada Media Group.

Wijono, S. (2010). Psikologi industri \& organisasi. Kencana.

https://daerah.sindonews.com/berita/1269943/174/perawat-mogok-kerja-pelayanan-rsud-akomamuju-utara-lumpuh 
Psikologi Prima

Vol 3, No 2 November 2020 e-ISSN : 2598 - 8026

https://megapolitan.kompas.com/read/2017/08/03/14064981/650-pegawai-jict-mogok-kerja https://www.cnnindonesia.com/nasional/20170501151335-20-211386/tuntutan-tak-dipenuhikaryawan-freeport-mogok-kerja-sebulan 